\title{
PERAN PEREMPUAN TERHADAP RUMAH TANGGA NELAYAN BURUH YANG BERAKTIVITAS DI TEMPAT PELELANGAN IKAN (TPI) TILAMUTA, KABUPATEN BOALEMO
}

\author{
Nolfin Diyata'; Victoria E.N. Manoppo2; Swenekhe S. Durand² \\ 1) Mahasiswa Fakultas Perikanan dan IImu Kelautan Universitas Sam Ratulangi, Manado. \\ 2) Staff Pengajar Fakultas Perikanan dan IImu Kelautan Universitas Sam Ratulangi, Manado. \\ Koresponden email: nolfindiyata@yahoo.com
}

\begin{abstract}
Boalemo's waters contain a variety of marine fish that have high economic value such as tuna, fish and mouse grouper. Realizing the potential of fishery owned, Fish Auction Place (TPI) which organizes fish sale with auction system is a place where Boalemo fishermen sell their fish catch.

The purpose of this study is to determine the general condition of women in households of fishermen who work at Tilamuta Fishing Place (TPI), Boalemo Regency and what are the roles of women in the household economy of fishermen who are active in the Fish Auction Site (TPI) Tilamuta, Kabupaten Boalemo.

The method used in this study used census method. Technique of data collecting is done by observation, interview, and literature study.

From the result of the research, most of the respondents have elementary school (SD) education as many as 14 people (70\%), productive age of respondent (15-45 years) as many as 18 people (90\%) and 4 families \%). The role of hunting women fishermen to meet the needs of family life consists of: Domestic role; 1) cooking, respondents doing cooking activities between 2-3 times in one day; 2) Washing clothes, respondents generally wash clothes 2 to 3 times and washed clothes are all family members; 3) Cleaning and tidying the house, in one day only done between 2 to 3 times; 4) Taking care of the children, respondents no longer prepare children's clothes and no longer deliver to school because the distance of school from home is close enough; 5) Helping the husband, the respondent to prepare the equipment to go to husband husband, market the catch of husband. Social Role: 1) Majelis Ta'lim, attending meetings 1-2 times a month, benefiting respondents; 2) Arisan, respondents do lott arisan 2 - 3 times a month, used to cover household needs; 3) Dasawisma and PKK, respondents have attended the meeting; 4) Kube, respondents have participated about 3 years, the result is used for family expenditure.

Productive Role: 1) Laborers, who work as laborers 3 to 4 days a week, earned wages ranging from Rp500,000 $R p 1,000,000$; 2) Private employees / civil servants, there is 1 person (5\%) with gajin only about> Rp1.000.000, -; 3) washcloth, there are 3 people (15\%) about $<2$ years, with wages $<R p 500.000$, -

Keywords: Role of women, Fish Auction Place, Tilamuta
\end{abstract}

\begin{abstract}
Abstrak
Perairan yang dimiliki Boalemo menyimpan berbagai ikan laut yang memiliki nilai ekonomis yang tinggi seperti tuna, ikan layang dan kerapu tikus. Menyadari akan potensi perikanan yang dimiliki, Tempat Pelelangan Ikan (TPI) yang menyelenggarakan jual beli ikan dengan sistem lelang ini menjadi tempat nelayan-nelayan Boalemo menjual hasil ikan tangkapan mereka.

Tujuan penelitian ini adalah untuk mengetahui keadaan umum perempuan pada rumah tangga nelayan buruh yang beraktivitas di Tempat Pelelangan Ikan (TPI) Tilamuta, Kabupaten Boalemo dan apa saja peran perempuan dalam perekonomian rumah tangga nelayan buruh yang beraktivitas di Tempat Pelelangan Ikan (TPI) Tilamuta, Kabupaten Boalemo.

Metode yang dipakai dalam penelitian ini dipakai metode sensus. Teknik pengumpulan data dilakukan dengan cara observasi, wawancara, dan studi literatur.

Dari hasil penelitian yang diperoleh kebanyakan responden memiliki pendidikan Sekolah Dasar (SD) sebanyak 14 orang $(70 \%)$, umur produktif responden (15-45 tahun) sebanyak 18 orang (90\%) serta jumlah tanggungan keluarga $<4$ orang sebanyak 16 orang $(80 \%)$.

Peran perempuan nelayan buru untuk memenuhi kebutuhan hidup keluarga terdiri dari: Peran domestik; 1) memasak, responden melakukan kegiatan memasak antara 2 - 3 kali dalam satu hari; 2) Mencuci pakaian, responden umumnya mencuci pakaian 2 sampai 3 kali dan pakaian yang dicuci adalah semua anggota keluarga; 3) Membersihkan dan merapikan rumah, dalam satu hari hanya dilakukan antara 2 sampai 3 kali; 4) Mengurus anak, responden sudah tidak lagi menyiapkan pakaian anak dan tidak lagi mengantar ke sekolah karena jarak sekolah dari rumah cukup dekat; 5) Membantu suami, responden menyiapkan perlengkapan melaut suami, memasarkan hasil tangkapan suami.

Peran Sosial: 1) Majelis Ta'lim, mengikuti pertemuan 1 - 2 kali dalam sebulan, memberikan manfaat bagi responden; 2) Arisan, responden melakukan lott arisan 2 - 3 kali sebulan, digunakan untuk menutupi keperluan rumah tangga; 3 )
\end{abstract}


Dasawisma dan PKK, responden sudah mengikuti pertemuan yang diadakan; 4) Kube, responden sudah ikut sekitar 3 tahun, hasilnya digunakana untuk belanja keperluan keluarga.

Peran Produktif : 1) Buruh, responden yang berkerja sebagai buruh 3 orang sampai 4 hari dalam satu minggu, upah yang diperoleh berkisar Rp500.000 - Rp1.000.000; 2) Pegawai Swasta/PNS, terdapat 1 orang (5\%) dengan gajin hanya sekitar >Rp1.000.000,-; 3) Tukas cuci, terdapat 3 orang (15\%) sekitar $<2$ tahun, dengan upah $<$ Rp500.000,--

Kata Kunci : Peranan perempuan, Tempat Pelelangan Ikan, Tilamuta

\section{PENDAHULUAN}

Kabupaten Boalemo merupakan salah satu Kabupaten di Provinsi Gorontalo dengan luas wilayah keseluruhan 2.300,90 $\mathrm{km}^{2}$. Daerah ini berbatasan langsung dengan Kabupaten Gorontalo di sebelah Utara dan Timur, Teluk Tomini di sebelah Selatan, Kabupaten Pohuwato di sebelah Barat.

Menyadari akan potensi perikanan yang dimiliki, Desa Tabulo di Kecamatan Mananggu dipilih sebagai lokasi utama untuk etalase perikanan, yang fungsi utama sebagai tempat penampungan ikan, ikan yang ditampung disini tidak hanya ikan-ikan hasil tangkapan nelayan Boalemo sendiri tapi juga nelayan di kawasan Timur Indonesia. Tempat Pelelangan Ikan (TPI) yang menyelenggarakan jual beli ikan dengan sistem lelang ini menjadi tempat nelayan-nelayan Boalemo

Peranan perempuan dalam pembangunan di segala bidang mutlak sangat diperlukan, karena merupakan sebagai modal dasar dalam pembangunan. Untuk mensejajarkan tenaga kerja perempuan dalam konsep-konsep kerja bukan semata-mata masalah kepentingan segi ekonomis atau peningkatan pendapatan, akan tetapi juga bertujuan untuk meningkatkan partisipasi atau peranan perempuan dalam masyarakat.

Keputusan yang diambil perempuan untuk bekerja merupakan sifat kewirausahaan yang muncul karena tekanan ekonomi dan kebutuhan keluarganya yang semakin meningkat (Mantjoro, 2014).

Rumah tangga nelayan buruh yang beraktivitas di Tempat Pelelangan Ikan (TPI) Tilamuta, Kabupaten Boalemo juga tidak terlepas dari situasi yang diuraikan diatas, sehingga perempuan sebagai istri mereka ikut mengambil bagian untuk mengatasi keadaan ekonomi dan kebutuhan keluarga mereka yang semakin meningkat demi peningkatan kesejahteraan mereka.

\section{Perumusan Masalah}

1. Bagaimana keadaan umum perempuan pada rumah tangga nelayan buruh yang beraktivitas di Tempat Pelelangan Ikan (TPI) Tilamuta, Kabupaten Boalemo?

2. Bagaimana peranan peran perempuan dalam rumah tangga nelayan buruh di Desa Pentadu Timur Kecamatan Tilamuta, Kabupaten Boalemo?

\section{Tujuan Penelitian}

Tujuan penelitian ini, yaitu :

1. Mengetahui keadaan umum perempuan pada rumah tangga nelayan buruh di Desa Petadu Timur Kecamatan Tilamuta, Kabupaten Boalemo.

2. Mengetahui apa saja peranan perempuan dalam rumah tangga nelayan buruh di Desa Pentadu Timur Kecamatan Tilamuta, Kabupaten Boalemo.

\section{Tempat dan Waktu Penelitian}

Penelitian ini bertempat di Desa Pentadu Timur Kecamatan Tilamuta, Kabupaten Boalemo, Provinsi Gorontalo. Waktu yang digunakan dalam pelaksanaan penelitian dimulai dari survei lokasi penelitian, konsultasi dan penyusunan Rencana Kerja Penelitian, pengumpulan data, konsultasi laporan sampai pada ujian, kurang lebih 4 bulan yaitu dimulai dari bulan Februari 2018 sampai dengan bulan Mei 2018. 


\section{METODE PENELITIAN}

Metode yang dipakai dalam penelitian ini metode sensus. Pengertian sensus adalah cara pengumpulan data apabila seluruh elemen populasi diselidiki satu per satu (Supranto, 2008). Jumlah responden 20 orang dan di dapat dari survei lapangan melalui petugas Tempat Pelelangan Ikan (TPI) dan observasi langsung. Jadi ke 20 orang sebagai populasi pada penelitian yang dilaksanakan. Jenis dan sumber data penelitian ini antara lain meliputi:

1. Data primer yaitu data yang diperoleh langsung dari lokasi penelitian melalui observasi dan wawancara dengan perempuan nelayan yang suaminya beraktivitas di Tempat Pelelangan Ikan (TPI) Tilamuta, menggunakan daftar pertanyaan (kuisioner) yang berjumlah 20 orang. Mereka menginginkan wawancara dilaksanakan di rumah meraka masing-masing yang dalam hal ini ke 20 orang responden tersebut semuanya bertampat tinggal di desa Pentadu Timur Kecamatan Tilamuta Kabupaten Boalemo.

2. Data sekunder yaitu data yang diperoleh dari instansi terkait dengan penelitian ini, seperti Dinas Perikanan Kabupaten Boalemo, Kantor Kecamatan Tilamuta setempat dan berbagai media yang ada melalui pencatatan.

Variabel yang diamati dalam penelitian ini adalah :

1. Guna menjawab tujuan penelitian pertama, variabel yang diteliti adalaha umur, tingkat pendidikan dan jumlah tanggungan keluarga.

2. Guna menjawab tujuan penelitian yang kedua, variable yang diteliti adalah peran perempuan nelayan buruh di sektor domestik dan sektor publik. Adapun variabel sektor domestik adalah memasak, mencuci pakaian, membersihkan dan merapikan rumah, mengurus anak, membantu suami suami, peran publik adalah Majelis Ta'alim, arisan, Dasawisma dan PKK, Kelompok Usaha Bersama (KUBE) dan peran produktif buruh, pegawai swasta/PNS, pengusaha, tukang cuci dan petibo.

Analisis data hasil penelitian dibedakan dalam dua macam, yaitu analisis kuantitatif dan analisis kualitatif. Analisis kuantitatif merupakan pengolahan data dengan menggunakan perhitungan matematis sederhana seperti penjumlahan, perkalian, pembagian dan persentase (\%). Sedangkan analisis kualitatif adalah pengolahan data yang dilakukan dengan bahasa-bahasa penulis yang sistematis.

Data yang telah dihitung kemudian diinterpretasikan sebagai hasil penelitian dan dibahas atau dikalimatkan menurut fakta lapangan, dengan mengacu pada jurnal-jurnal hasil penelitian yang berkaiatan dengan penelitian ini (Sugiyono, 2010).

\section{HASIL DAN PEMBAHASAN}

\section{Keadaan Umum Responden}

Hasil penelitian menunjukkan bahwa responden ada yang bekerja Tukang cuci, buruh, PNS. Lebih lengkapnya dapat dilihat pada Tabel 1 berikut ini.

Tabel 1. Jumlah Responden Menurut Jenis Pekerjaan

\begin{tabular}{clcc}
\hline No & Jenis Pekerjaan & $\begin{array}{c}\text { Jumlah } \\
\text { (Orang) }\end{array}$ & $\begin{array}{c}\text { Presentase } \\
(\%)\end{array}$ \\
\hline 1 & Tukang cuci + IRT & 3 & 15 \\
2 & Buruh+ IRT & 2 & 10 \\
3 & PNS + IRT & 1 & 5 \\
4 & Ibu Rumah Tangga & 14 & 70 \\
\hline \multicolumn{1}{c}{ Jumlah } & $\mathbf{2 0}$ & $\mathbf{1 0 0}$ \\
\hline
\end{tabular}

Sumber : Hasil pengolahan data primer, 2018

Pada tabel 1 menenunjukan
bahwa tukang cuci melakukan 
pekerjaannya pada pagi hari setelah melakukan pekerjaan tersebut dia kembali kerumah untuk melakukan aktivitasnya sebagai ibu rumah tangga. Hasil upah yang diperoleh dari pekerjaan ini digunakan untuk mencukupi kebutuhan keluarga, yang bekerja sebagai buruh melakukan pekerjaannya pada pagi dan siang hari, hasil dari upah bekerja buruh digunakan untuk belanja keperluan anak, PNS melakukan pekerjaannya pada pagi sampai sore hari, upah yang diperoleh untuk tabungan keluarga.

\section{Pendidikan}

Untuk lebih jelasnya mengenai keadaan responden berdasarkan tingkat pendidikan dapat dilihat pada Tabel 2.

Tabel 2. Keadaan Responden Berdasarkan Tingkat Pendidikan

\begin{tabular}{ccc}
\hline $\begin{array}{c}\text { Tingkat } \\
\text { pendidikan }\end{array}$ & $\begin{array}{c}\text { Responden } \\
\text { (orang) }\end{array}$ & $\begin{array}{c}\text { Persentase } \\
\text { (\%) }\end{array}$ \\
\hline SD & 14 & 70 \\
SMP & 5 & 25 \\
SMA & - & - \\
SARJANA & 1 & 5 \\
\hline Total & $\mathbf{2 0}$ & $\mathbf{1 0 0}$ \\
\hline
\end{tabular}

Sumber : Hasil Pengolahan Data Primer, 2018

Tabel 2 menunjukkan bahwa responden berpendidikan Sekolah Dasar (SD) sebanyak 14 orang (70\%), yang berpendidikan Sekolah Menengah Pertama (SMP) sebanyak 5 orang (25\%), berpendidikan Sekolah Menengah Atas (SMA) $0(0 \%)$ dan berpendidikan Sarjana sebanyak 1 orang $(5 \%)$. Dari gambaran ini menunjukan bahwa ketidak mampuan melanjutakan ketingkat lebih tinggi karena keadaan perekonomian keluaraga yang minim pada waktu itu tapi dengan pendidikan yang rendah ini bisa membantu perekonmian keluarga melalui pekerjaan sebagai tukang cuci dan buruh di Tempat Pelelangan Ikan (TPI).

\section{Umur}

Hasil penelitian umur ini dibagi dalam dua klasifikasi yaitu umur produktif dan kurang produktif. Untuk lebih jelasnya dapat dilihat pada Tabel 3.

Tabel 3. Identitas Responden Menurut Kelompok Umur

\begin{tabular}{|c|c|c|}
\hline $\begin{array}{c}\text { Umur } \\
\text { (tahun) }\end{array}$ & $\begin{array}{l}\text { Responden } \\
\text { (orang) }\end{array}$ & $\begin{array}{c}\text { Persentase } \\
(\%)\end{array}$ \\
\hline Produktif (15- 54) & 18 & 90 \\
\hline $\begin{array}{l}\text { Kurang Produktif } \\
(>54)\end{array}$ & 2 & 10 \\
\hline Total & 20 & 100 \\
\hline
\end{tabular}

Sumber : Hasil Pengolahan Data Primer, 2018

Tabel 3 menunjukkan jumlah usia produktif perempuan responden lebih banyak yakni sebanyak 18 orang (90\%) dibanding dengan usia kurang produktif yang hanya 2 orang (10\%).

Sebanyak $90 \%$ masih melakukan pekerjaan yang menghasilkan sesuatu misalnya bekerja sebagai tukang cuci dan buruh nelayan. Mereka masih memiliki kemampuan menghasilkan atau mendapatkan upah dari hasil kerja mereka untuk membantu suami dalam mengatasi kebutuhan keluarga.

\section{Jumlah Tanggungan Keluarga}

Tanggungan keluarga merupakan salah satu alasan utama bagi para perempuan dalam sebuah rumah tangga turut serta membantu suami dan memutuskan untuk bekerja sehingga memperoleh penghasilan.

Untuk lebih jelasnya keadaan responden berdasarkan jumlah tanggungan dapat dilihat pada Tabel 4.

Tabel 4. Keadaan Responden Berdasarkan Jumlah Tanggungan Keluarga di Tilamuta

\begin{tabular}{ccc}
\hline $\begin{array}{c}\text { Jumlah } \\
\text { tanggungan } \\
\text { keluarga } \\
\text { (orang) }\end{array}$ & $\begin{array}{c}\text { Responden } \\
\text { (orang) }\end{array}$ & $\begin{array}{c}\text { Persentase } \\
\mathbf{( \% )}\end{array}$ \\
\hline $4-6$ & 4 & 20 \\
$<4$ & 16 & 80 \\
\hline Total & $\mathbf{2 0}$ & $\mathbf{1 0 0}$ \\
\hline
\end{tabular}

Sumber : Hasil Pengolahan Data Primer, 2018 
Tabel 4 menunjukkan jumlah tanggungan keluarga perempuan responden yang beraktivitas di Tempat Pelelangan Ikan (TPI) Tilamuta sebagian besar tergolong dalam kategori keluarga sedang yakni 16 orang $(80 \%)$ dan disusul oleh kategori keluarga kecil yaitu sebanyak 4 orang (20\%). Artinya bahwa konsekuensi alokasi tenaga kerja dan pendapatan responden cukup besar untuk memenuhi kebutuhan keluarga baik untuk konsumsi maupun untuk kepentingan lain seperti pendidikan, kesehatan dan lain sebagainya.

\section{Peran Perempuan Nelayan Buruh Dalam Pemenuhan Kebutuhan Hidup Keluarga}

Perempuan mempunyai beban lebih banyak jika dibandingkan dengan laki-laki. Hal tersebut dikarenakan adanya budaya patriarki dalam masyarakat yang menempatkan laki-laki pada posisi yang lebih tinggi, sehingga beban pekerjaan rumah tangga senantiasa dilimpahkan kepada perempuan. Menurut hasil penelitian, perempuan pedagang ikan memiliki peran dalam sektor domestik, produktif dan sosial kemasyarakatan Gude (2017).

Tabel 5. Peran Domestik Perempuan Nelayan Buruh Dalam Pemenuhan Kebutuhan Hidup Keluarga (Memasak)

\begin{tabular}{|c|c|c|c|}
\hline \multicolumn{2}{|r|}{ Memasak } & $\begin{array}{l}\text { Jumlah } \\
\text { (orang) }\end{array}$ & $\begin{array}{c}\text { Persentase } \\
(\%)\end{array}$ \\
\hline \multicolumn{4}{|c|}{ a. Dalam sebulan } \\
\hline & $->20$ kali & 20 & 100 \\
\hline & - 10-19 kali & - & - \\
\hline & $-<10$ kali & - & - \\
\hline \multicolumn{4}{|c|}{ b. Dalam sehari } \\
\hline & - 3 kali & 1 & 5 \\
\hline & - 2 kali & 7 & 35 \\
\hline & - 1 kali & 12 & 60 \\
\hline \multirow[t]{4}{*}{ c. } & pernah & & \\
\hline & membantu & 9 & 45 \\
\hline & - Tidak & 4 & 20 \\
\hline & $\begin{array}{l}\text { - Kadang-kadang } \\
\text { - Ya }\end{array}$ & 7 & 35 \\
\hline d. & membantu & & \\
\hline
\end{tabular}

\begin{tabular}{lcc} 
memasak & 6 & 30 \\
- Suami lbu & 6 & 30 \\
- Anak lbu & 8 & 40 \\
- lbu & & \\
\hline Jumlah responden & 20 & 100 \\
\hline \multicolumn{2}{l}{ Sumber Hasil Pengolahan Data Primer, 2018 }
\end{tabular}

Pada Tabel 5 dapat dibaca bahwa peran perempuan responden pada umunya melaksanakan peran memasak sendiri tidak dibantu oleh suami ataupun pembantu rumah tangga dan perempuan responden melakukan kegiatan memasak antara 2 sampai 3 kali dalam waktu satu hari. Responden yang memasak 3 kali, memasaknya dalam waktu pagi, siang dan sore sedangkan yang memasak 2 kali hanya memasak di waktu pagi dan sore saja dan yang dimasak beragam dimulai dari nasi beserta lauk pauknya (ikan dan sayur).

Tabel 6. Peran Domestik Perempuan Nelayan Buruh Dalam Pemenuhan Kebutuhan Hidup Keluarga (Mencuci Pakaian)

\begin{tabular}{|c|c|c|c|}
\hline & Mencuci Pakaian & $\begin{array}{l}\text { Jumlah } \\
\text { (orang) }\end{array}$ & $\begin{array}{c}\text { Persentase } \\
(\%)\end{array}$ \\
\hline \multirow[t]{4}{*}{ a. } & Dalam seminggu & & \\
\hline & - 3 kali & 13 & 65 \\
\hline & - 2 kali & 6 & 30 \\
\hline & - 1 kali & 1 & 5 \\
\hline \multirow[t]{4}{*}{ b. } & Mengangkut air & & \\
\hline & - Ya & - & - \\
\hline & - Kadang-kadang & - & - \\
\hline & - Tidak & 20 & 100 \\
\hline \multirow[t]{4}{*}{ c. } & Pakaian yang dicuci & & \\
\hline & - Semua anggota & 20 & 100 \\
\hline & keluarga & - & - \\
\hline & $\begin{array}{l}\text { - Suami dan anak } \\
\text { - Pakaian sendiri }\end{array}$ & - & - \\
\hline \multirow[t]{4}{*}{ d. } & Yang membantu & & \\
\hline & mencuci & 2 & 10 \\
\hline & - Saudara & 10 & 50 \\
\hline & $\begin{array}{l}\text { - Anak } \\
\text { - Ibu }\end{array}$ & 8 & 40 \\
\hline \multicolumn{2}{|c|}{ Jumlah responden } & 20 & 100 \\
\hline
\end{tabular}


Tabel 7. Peran Domestik Perempuan Nelayan Buruh Dalam Pemenuhan Kebutuhan Hidup Keluarga (Membersihkan dan Merapikan Rumah)

\begin{tabular}{lcc}
\hline $\begin{array}{l}\text { Membersihkan dan } \\
\text { Merapikan Rumah }\end{array}$ & $\begin{array}{c}\text { Jumlah } \\
\text { (orang) }\end{array}$ & $\begin{array}{c}\text { Persentase } \\
\text { (\%) }\end{array}$ \\
\hline a. Menyapu rumah dalam & & \\
sehari & 9 & 45 \\
- 3 kali & 10 & 50 \\
- 2 kali & 1 & 1 \\
- 1 kali & & \\
b. Mengepel lantai rumah & & \\
dalam sehari & 9 & 45 \\
- 3 kali & 10 & 50 \\
- 2 kali & 1 & 1 \\
- 1 kali & & \\
c. Suami membantu & & \\
- Tidak & 3 & 15 \\
- Kadang-kadang & 9 & 45 \\
- Ya & 8 & 40 \\
d. Yang membantu & & \\
- Suami & 4 & 20 \\
- Anak & 8 & 40 \\
- Ibu sendiri & 8 & 40 \\
\hline Jumlah responden & 20 & 100 \\
\hline Sumber : Hasil Pengolahan Data Primer, 2018
\end{tabular}

Hasil di atas diperoleh dari jumlah responden menyapu dan mengepel dalam satu hari jika responden menyapu dan mengepel dan Tabel 7 di atas menunjukkan bahwa perempuan responden dalam membersihkan dan merapikan rumah atau menyapu dan mengepel dalam satu hari hanya dilakukan antara 2 sampai 3 kali dan suami tidak pernah terlibat dalam kegiatan ini.

Tabel 8. Peran Domestik Perempuan Nelayan Buruh Dalam Pemenuhan Kebutuhan Hidup Keluarga (Mengurus Anak)

\begin{tabular}{|c|c|c|}
\hline Mengurus Anak & $\begin{array}{l}\text { Jumlah } \\
\text { (orang) }\end{array}$ & $\begin{array}{c}\text { Persentase } \\
(\%)\end{array}$ \\
\hline a. Menyiapkan pakaian & & \\
\hline anak & 8 & 40 \\
\hline - $Y a$ & - & - \\
\hline $\begin{array}{l}\text { - Kadang-kadang } \\
\text { - Tidak }\end{array}$ & 12 & 60 \\
\hline Jumlah responden & 20 & \\
\hline b. Mengantar anak ke & & \\
\hline Sekolah & 8 & 40 \\
\hline$-Y a$ & - & - \\
\hline $\begin{array}{l}\text { - Kadang-kadang } \\
\text { - Tidak }\end{array}$ & 12 & 60 \\
\hline Jumlah responden & 20 & \\
\hline $\begin{array}{l}\text { c. Suami membantu } \\
-Y_{a}\end{array}$ & - & - \\
\hline
\end{tabular}

\begin{tabular}{lcc} 
- Kadang-kadang & - & - \\
- Tidak & 20 & 100 \\
\hline Jumlah responden & 20 & 100 \\
\hline Sumber : : Hasil Pengolahan Data Primer, 2018 \\
Tabel 8 di atas menunjukkan bahwa \\
peran perempuan responden dalam hal \\
mengurus anak di sini dilihat dari \\
keterlibatan responden menyiapkan \\
pakaian anak sebelum berangkat sekolah \\
serta mengantar langsung ke sekolah.
\end{tabular}

Tabel 9. Peran Domestik Perempuan Nelayan Buruh Dalam Pemenuhan Kebutuhan Hidup Keluarga (Membantu Suami)

\begin{tabular}{|c|c|c|c|}
\hline & Membantu Suami & $\begin{array}{l}\text { Jumlah } \\
\text { (orang) }\end{array}$ & $\begin{array}{c}\text { Persentase } \\
(\%)\end{array}$ \\
\hline \multirow[t]{4}{*}{ a. } & Mengantar ke tempat & & \\
\hline & kerja & 8 & 40 \\
\hline & - Ya & 1 & 5 \\
\hline & $\begin{array}{l}\text { - Kadang-kadang } \\
\text { - Tidak }\end{array}$ & 11 & 55 \\
\hline \multirow[t]{4}{*}{ b. } & Mengantar suami & & \\
\hline & bekerja di luar & 5 & 25 \\
\hline & - $Y a$ & 1 & 5 \\
\hline & $\begin{array}{l}\text { - Kadang-kadang } \\
\text { - Tidak }\end{array}$ & 14 & 70 \\
\hline \multirow[t]{4}{*}{ c. } & Memberi bekal & & \\
\hline & - Ya & 14 & 70 \\
\hline & - Kadang-kadang & - & - \\
\hline & - Tidak & 6 & 30 \\
\hline & nlah responden & 20 & 100 \\
\hline
\end{tabular}

Tabel 9 menunjukkan bahwa peran perempuan dalam hal membantu suami disini dilihat dapat dilihat pada Tabel 9 didominasi kategori sedang hal ini disebabkan karena responden kadang terlibat tapi tidak selalu terlibat dalam hal menyiapakan perlengkapan dan bekal suami, mengantar suami ke TPI.

\section{Peran Sosial}

Selanjutnya peran sosial perempuan dapat dibaca pada tabel 10.

Tabel 10.Peran Sosial Perempuan Nelayan Buruh Dalam Pemenuhan Kebutuhan Hidup Keluarga (Majelis Ta'lim)

\begin{tabular}{|c|c|c|}
\hline Majelis Ta'lim & $\begin{array}{l}\text { Jumlah } \\
\text { (orang) }\end{array}$ & $\begin{array}{c}\text { Persentase } \\
\text { (\%) }\end{array}$ \\
\hline a. Bergabung & & \\
\hline $\begin{array}{l}\text { majelis ta'lim } \\
-\quad Y a\end{array}$ & $\begin{array}{l}20 \\
-\end{array}$ & 100 \\
\hline
\end{tabular}


- Kadang-kadang

- Tidak

b. Dalam bulan

- 3 kali $\begin{array}{ll}5 & 25 \\ 8 & 40 \\ 7 & 35\end{array}$

- 2 kali $\begin{array}{ll}5 & 25 \\ 8 & 40 \\ 7 & 35\end{array}$

- 1 kali

c. Pendapat ibu

- Bermanfaat dan aktif $20 \quad 100$

- Kurang bermanfaat

- Belum aktif / tidak aktif

\begin{tabular}{lll}
\hline Jumlah responden & 20 & 100
\end{tabular}

Sumber : : Hasil Pengolahan Data Primer, 2018

Tabel 10 menunjukkan bahwa peran sosial perempuan responden dalam hal kelompok majelis dalam penelitian ini dilihat dari keikut sertaan responden dalam kelompok Majelis Ta'lim, jumlah pertemuan (kajian) kelompok Majelis Ta'lim dalam satu bulan dan tanggapan responden tentang keberadaan kelompok Majelis Ta'lim tersebut apakah sudah aktif dan bermanfaat atau tidak.

Tabel 11.Peran Sosial Perempuan Nelayan Buruh Dalam Pemenuhan Kebutuhan Hidup Keluarga (Arisan)

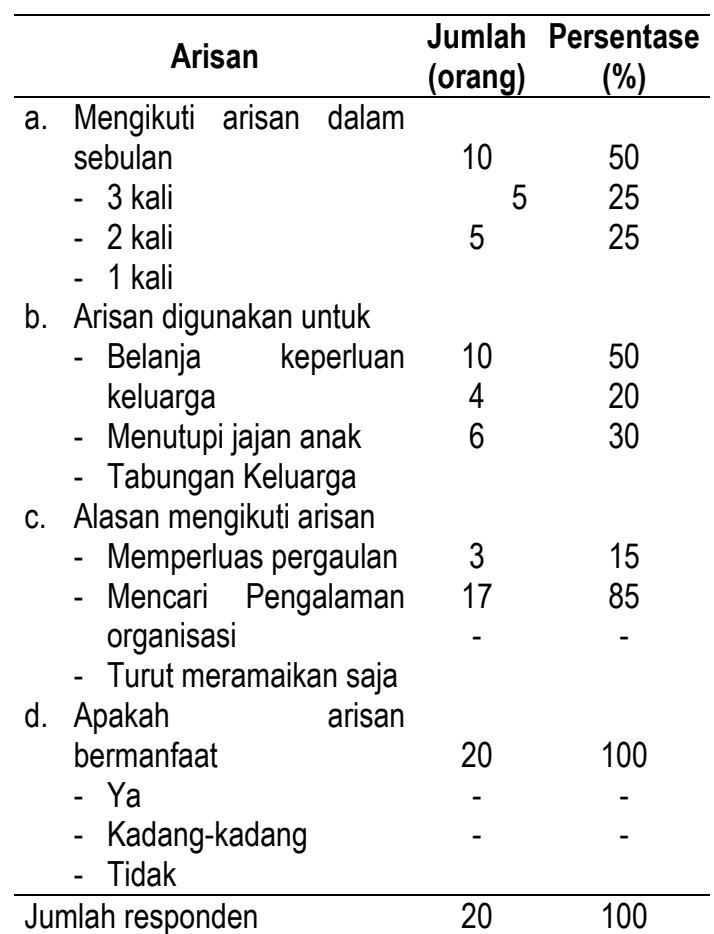

Sumber : Hasil Pengolahan Data Primer, 2018

Hasil penelitian bahwa perempuan responden melakukan arisan 2 sampai 3 kali dalam satu bulan, hasil dari arisan digunakan untuk menutupi keperluan rumah tangga dan motivasi responden utnuk mencari pengalaman organisasi dan memperluas pengalaman.

Tabel 12. Peran Sosial Perempuan Nelayan Buruh Dalam Pemenuhan Kebutuhan Hidup Keluarga (Dasawisma dan PKK)

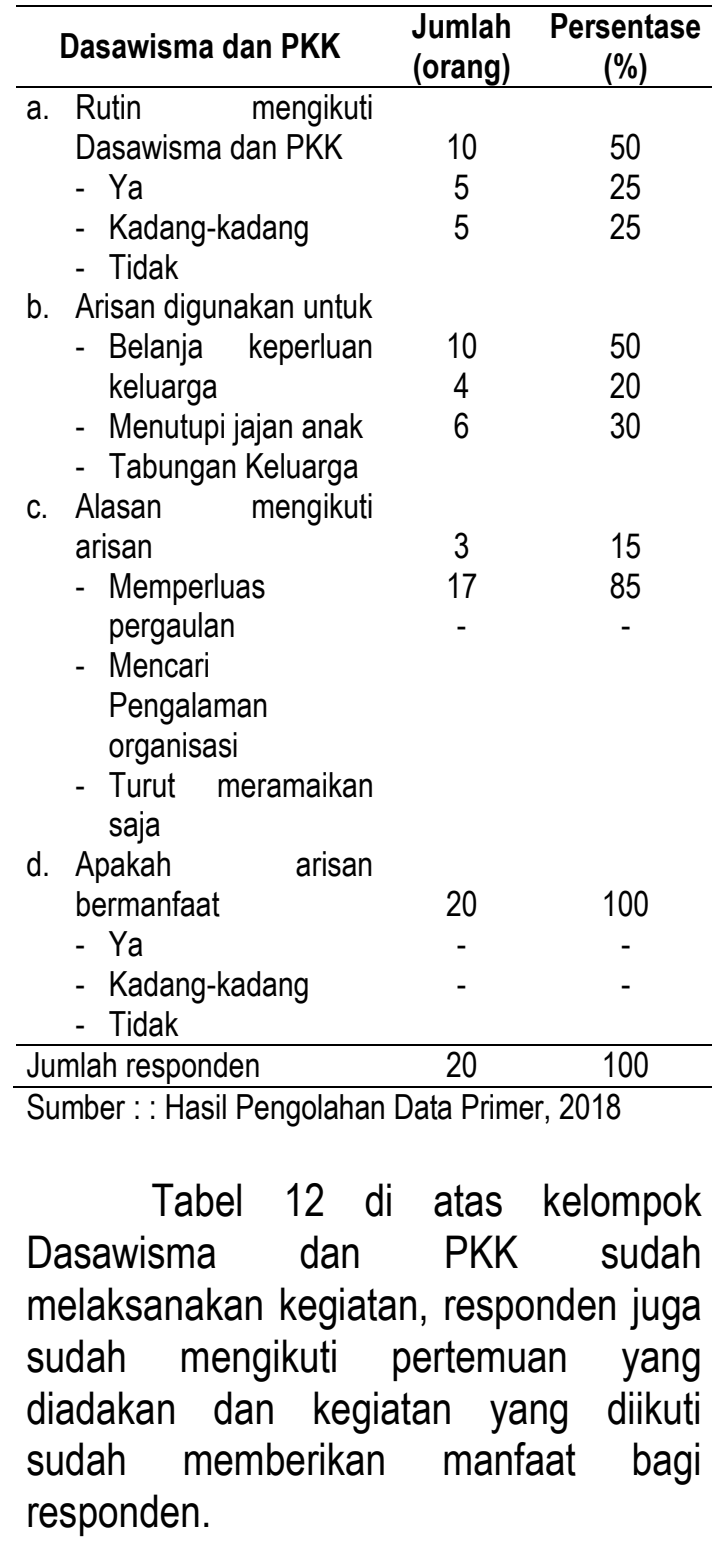

\section{Peran Produktif}

Peran ini diidentikan sebagai peran perempuan di sektor publik, contoh petani, penjahit, buruh, guru, pengusaha,kelompok usaha bersama (kube),tukang cuci. Peran produktif perempuan nelayan dapat dilihat pada tabel berikut ini.

Tabel 13.Peran Produktif Perempuan Nelayan Buruh dalam kelompok usaha bersama (KUBE) 


\begin{tabular}{|c|c|c|c|}
\hline Kube & $\begin{array}{c}\text { Jlh } \\
\text { (org) }\end{array}$ & $(\%)$ & $\begin{array}{c}\text { Jumlah } \\
(\%)\end{array}$ \\
\hline \multicolumn{4}{|l|}{\begin{tabular}{|l|} 
Kube \\
\end{tabular}} \\
\hline \begin{tabular}{|l} 
a. \\
- 3 tahu bergabung \\
-2 tahun \\
-1 tahun \\
\end{tabular} & $\begin{array}{l}8 \\
7 \\
5 \\
\end{array}$ & $\begin{array}{l}40 \\
35 \\
25 \\
\end{array}$ & 100 \\
\hline 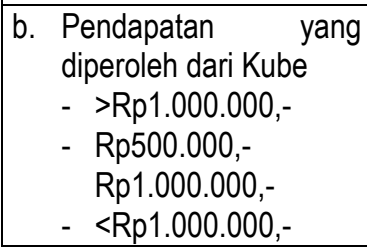 & $\begin{array}{l}7 \\
8 \\
5\end{array}$ & $\begin{array}{l}35 \\
40 \\
25\end{array}$ & 100 \\
\hline $\begin{array}{l}\text { c. Kube bermanfaat bagi } \\
\text { keluarga } \\
\text { - Ya } \\
\text { - Kadang-kadang } \\
\text { - Tidak }\end{array}$ & $\begin{array}{l}20 \\
- \\
-\end{array}$ & $\begin{array}{c}100 \\
- \\
-\end{array}$ & 100 \\
\hline $\begin{array}{ll}\text { d. Hasil dari Kube } \\
\text { digunakan untuk } \\
\text { - Belanja keperluan } \\
\\
\text { keluarga } \\
\text { - Menutupi jajan anak } \\
\text { - Tabungan keluarga }\end{array}$ & $\begin{array}{c}10 \\
4 \\
6\end{array}$ & $\begin{array}{l}50 \\
20 \\
30\end{array}$ & 100 \\
\hline Jumlah responden & 20 & & \\
\hline
\end{tabular}

Sumber : : Hasil Pengolahan Data Primer, 2018

Tabel 13 menunjukkan bahwa peran perempuan responden dalam KUBE ini dilihat dari seberapa lama responden ikut serta dalam KUBE tersebut, berapa hasil yang diperoleh dari KUBE tersebut serta apakah KUBE ini sudah berdampak pada perekonomian keluarga atau belum.

Tabel 14. Peran Produktif Perempuan Nelayan

Buruh Dalam Pemenuhan Kebutuhan Hidup Keluarga (Buruh)

\begin{tabular}{|c|c|c|}
\hline Buruh & $\begin{array}{l}\text { Jumlah } \\
\text { (orang) }\end{array}$ & $\begin{array}{c}\text { Persentase } \\
(\%)\end{array}$ \\
\hline $\begin{array}{l}\text { a. } \\
\text { Dalam seminggu } \\
\text { - Setiap hari } \\
\text { - 3-4 hari } \\
\text { - Yang tidak bekerja } \\
\text { sebagai buruh }\end{array}$ & $\begin{array}{c}2 \\
- \\
18\end{array}$ & $\begin{array}{c}10 \\
- \\
90\end{array}$ \\
\hline $\begin{array}{l}\text { b. Pendapatan yang } \\
\text { diperoleh dari buruh } \\
\text { - }>\text { Rp1.000.000,- } \\
\text { - Rp500.000,- } \\
\text { Rp1.000.000,- } \\
\text { - Yang tidak bekerja } \\
\text { sebagai buruh }\end{array}$ & $\begin{array}{c}- \\
2 \\
18\end{array}$ & $\begin{array}{c}- \\
10 \\
90\end{array}$ \\
\hline $\begin{array}{l}\text { c. Kube bermanfaat bagi } \\
\text { keluarga } \\
\text { - Ya } \\
\text { - Tidak } \\
\text { - Yang tidak bekerja } \\
\text { sebagai buruh }\end{array}$ & $\begin{array}{c}2 \\
- \\
18\end{array}$ & $\begin{array}{c}10 \\
- \\
90\end{array}$ \\
\hline
\end{tabular}

\begin{tabular}{|l|c|c|}
\hline d. Hasil dari Buruh & & \\
digunakan untuk & 2 & 10 \\
- Belanja keperluan & - & - \\
keluarga & 18 & 90 \\
- Menutupi jajan anak & & \\
- Yang tidak bekerja & & \\
- sebagai buruh & &
\end{tabular}

Sumber : : Hasil Pengolahan Data Primer, 2018

Tabel 14 di atas menunjukkan bahwa dari 20 orang responden hanya 2 orang atau $10 \%$ yang bekerja sebagai buruh, pengkategorian peran perempuan responden dalam hal bekerja sebagai buruh dilihat dari jumlah hari kerja responden dalam satu minggu, upah yang diperoleh responden dari bekerja sebagai buruh dan apakah upah tersebut sudah dapat menutupi kekurangan pemasukan suami.

Tabel 15. Peran Produktif Perempuan Nelayan Buruh Dalam Pemenuhan Kebutuhan Hidup Keluarga (Tukang Cuci)

\begin{tabular}{|c|c|c|}
\hline Tukang Cuci & $\begin{array}{l}\text { Jumlah } \\
\text { (orang) }\end{array}$ & $\begin{array}{c}\text { Persentase } \\
(\%)\end{array}$ \\
\hline \begin{tabular}{|l} 
a. Lama bekerja \\
$->5$ tahun \\
$-2-5$ tahun \\
$-<2$ tahun \\
- Tidak bekerja sebagai \\
tukang cuci
\end{tabular} & $\begin{array}{c}- \\
- \\
3 \\
17\end{array}$ & $\begin{array}{c}- \\
- \\
15 \\
85\end{array}$ \\
\hline \begin{tabular}{|l} 
b. \\
Pendapatan yang \\
diperoleh dari tukang \\
cuci \\
- >Rp1.500.000,- \\
- Rp1.000.000,-- \\
Rp1.500.000,- \\
- <Rp 500.000,- \\
- Tidak bekerja sebagai \\
tukang cuci \\
\end{tabular} & $\begin{array}{c}- \\
- \\
3 \\
17\end{array}$ & $\begin{array}{c}- \\
- \\
15 \\
85\end{array}$ \\
\hline $\begin{array}{ll}\text { c. } & \text { Motivasi bekerja } \\
\text { - } & \text { menjalani karir } \\
\text { - } & \text { membantu suami } \\
& \text { mencari nafkah } \\
\text { - } & \text { mencukupi kebutuhan } \\
& \text { rumah tangga } \\
\text { - } & \text { Yang tidak bekerja } \\
& \text { sebagai tukang cuci }\end{array}$ & $\begin{array}{c}- \\
- \\
3 \\
17\end{array}$ & $\begin{array}{c}- \\
- \\
15 \\
85\end{array}$ \\
\hline
\end{tabular}

Sumber : Hasil Pengolahan Data Primer, 2018

Tabel 15 di atas menujukkan bahwa dari 20 orang responden hanya ada 3 orang atau $15 \%$ yang menjadi tukang cuci. Pengkategorian pada Tabel 15 dilihat dari berapa lama responden sebagai tukang cuci, berapa gaji yang diperoleh dan 
alasan atau motivasi responden sehingga menjadi tukang cuci.

\section{KESIMPULAN DAN SARAN Kesimpulan}

Berdasarkan uraian hasil
penelitian, maka dapat ditarik
kesimpulan sebagai berikut:

1. Keadaan umum perempuan pada rumah tangga nelayan buruh yang beraktivitas di Tempat Pelelangan Ikan (TPI) Tilamuta, Kabupaten Boalemo adalah berpendidikan Sekolah Dasar (SD) sebanyak 14 orang $(70 \%)$, yang berpendidikan Sekolah Menengah Pertama (SMP) sebanyak 5 orang $(25 \%)$, berpendidikan Sekolah Menengah Atas (SMA) $0(0 \%)$ dan berpendidikan Sarjana sebanyak 1 orang $(5 \%)$.

2. Peranan perempuan terhadap rumah tangga nelayan buruh yang beraktivitas di Tempat Pelelangan Ikan (TPI) Tilamuta Kabupaten Boalemo ternyata sangat besar baik peran domestik, peran sosial maupun produktif.

\section{Saran}

1. Kepada perempuan nelayan sebaiknya tetap mempertahankan jika bisa ditingkatkan perannya di sektor domestik dan lebih ditingkatkan pada sektor publik. Dengan kata lain jangan ragu untuk ikut serta dalam kelompok- kelompok sosial masyarakat.

2. Kepada pemerintah khususnya Dinas Kelautan dan Perikanan serta Bidang Pemberdayaan Masyarakat agar mengintensifkan programprogram pemberdayaan masyarakat khususnya perempuan yang dapat menunjang dan menambah pendapatan suami yang minim.

\section{DAFTAR PUSTAKA}

Alfian. 2006. Peningkatan Ekonomi Rumah Tangga Nelayan Melalui Pemberdayaan Perempuan Nelayan. http://fpik.bunghatta.ac.id/file s/downloads/Jurnal\%20 Mang rove\%20\&\%20Pesisir/1_alfia n.pdf. Journal Mangrove dan pesisir Vol: VI. No 1/2006. Hal 2. Diakses tanggal 23 april 2018 jam 20.59 .

Dahuri, R. 2009. Strategi Pengembangan Industri Pariwisata Bahari. Jurnal Perikanan dan Kelautan.

Departemen Kelautan dan Perikanan, 2006. Pedoman Umum Kelembagaan Tempat Pelelangan Ikan. Direktoat Pemesaran Dalam Negeri. Direktorat Jenderal Pengolahan dan Pemasaran Hasil Perikanan. Jakarta: Departemen Kelautan dan Perikanan Republik Indonesia.

Departemen Kelautan dan Perikanan. 2006. Peraturan Menteri Kelautan dan Perikanan Nomor PER. 16/MEN/2006 tentang Pelabuhan Perikanan.

Gude, I. 2017. Analisis Peran Perempuan Pada Rantai Nilai Pemasaran Ikan Tuna Cakalang di Tempat Pelelangan Ikan (TPI) Aertembaga Kota Bitung. Jurnal Alkuturasi , Vol. 5 No. 9 (April 2017), ISSN. 2337-4195. . Diakses tanggal 22 april 2018 jam 21.59.

Harijani, D.R. 2001. Etos Kerja Perempuan Desa. Yogyakarta, Philoshophi Press.

Mantjoro, E. 2014. Ekonomi Sumberdaya Perikanan. Fakultas Perikanan dan IImu Kelautan. Universitas Sam Ratulangi. Manado.

Notopuro, H. 2004. Identifikasi Strategi Pemberdayaan Bidang Ekonomi. Jurnal Pemberdayaan Perempuan, Jakarta.

Puspitawati H. 2009. Konsep dan Teori Gender [diktat]. Bogor: Departemen IImu Keluarga dan Konsumen, Fakultas Ekologi Manusia. Institut Pertanian Bogor. 
AKULTURASI

Available online :http://ejournal.unsrat.ac.id/index.php/akulturasi 